Editorial

\title{
Connecting ecological science and management in forests for scientists, managers and pocket scientists
}

\section{Introduction}

The structures, patterns, and processes of the forests of the world develop from ecological interactions among hugely diverse types of organisms interacting with environmental factors at specific places and times on the Earth's surface. The science of ecology helps us develop frameworks for understanding these structures, patterns and processes, leading to descriptive studies and experiments that increase our insights into the nature of forests across space and time. Forest management changes the structure, patterns, and processes of forests, produce goods and services for people. These activities may be informed by scientific insights, though forest management has a much longer history than ecological science.

Modern forest management relies heavily on insights from ecological science. Management approaches may call for the use of "the best available science," but the dynamics of real forests may not be very deterministic and more flexible views of science and management may be productive (cf. Aplet and McKinley, 2017, Matonis et al., 2017). Various simple characterizations might represent the classical framework of ecological insight informing forest management (Fig. 1). In this Editors Note from the IUFRO Regional Congress for Asia and Oceania in Beijing in 2016, we suggest that a more effective framing is possible, where science and management are developed in interacting, powerful ways. We develop these ideas with two examples where science was used to inform management, and then flip the direction with two examples of how landscape-scale managed forests led to improved scientific understanding. The idea of "pocket science" is developed as an explicit approach that helps forest managers pull science and management together at the scale of forest operations, enhancing both understanding and management.

\section{Classic science experimental design}

Forest research often uses classical experimental designs with treatments applied to replicate plots within a single stand. The choice of locating all replicates (degrees of freedom) stems from a desire to minimize variation among plots, allowing the signal of the treatment response to be detected more clearly. Insights from these experiments may apply to other forests and other times if other ecological factors do not interact with the factors examined in the classic experimental design.

\subsection{Biogeochemistry in fast-growing Eucalyptus plantations}

Highly productive plantations Eucalyptus species are commonly established on low-fertility soils, and large nutrient exports at the harvest every 6-7 years pose a challenge for sustainability (Gonçalves et al., 2013). Large amounts of fertilizers are applied to increase nutrient supply and countered losses in forest harvest (Stape et al., 2006, 2010). How does the addition of fertilizers change the cycling of elements in forests and soils? Are the added nutrients retained in the soil, in the trees, or lost by leaching during the rainy seasons? How long after fertilization are rates of nutrient cycling increased? How variable would these responses be around the world? The scientific curiosity behind these questions has led to experiments that may be quite valuable for sustaining high growth rates in plantations. Matching fertilization regimes to tree requirements requires improving our understanding of the biogeochemical processes controlling the dynamics of nutrient availability in soils.

Comprehensive studies have been carried out in the Congo and in Brazil for contrasting nutrient supplies to quantify the main fluxes of N, P, K, Ca and $\mathrm{Mg}$ at the scale of the ecosystem in Eucalyptus plantations, from planting to harvesting (for details, see Laclau et al., 2010). These plantations are typically established on very deep soils, and Eucalyptus roots descend deep into the soil almost at the rate the crowns rise into the air. Soil mineralogy as well as the main soil physical and chemical properties have been characterized down to depths $>5 \mathrm{~m}$. Nutrient accumulation in the trees, nutrient returns to soil with litterfall and nutrient releases during litter decomposition were also measured throughout stand rotation. Moreover, the nutrient fluxes dissolved in gravitational solutions were quantified to assess the losses by deep drainage after clear-cutting and to provide practical recommendations for the fertilization regimes.

Strong differences in soil, climate, eucalypt species and silvicultural practices between the commercial eucalypt plantations at the two sites led to much higher productivities in Brazil (about $50 \mathrm{~m}^{3} \mathrm{ha}^{-1} \mathrm{yr}^{-1}$ ) than in the Congo (about $20 \mathrm{~m}^{3} \mathrm{ha}^{-1} \mathrm{yr}^{-1}$ ). Although the soils in both locations was predominantly sand (90\% sand in the Congo, 75-80\% sand in Brazil), nutrient losses in deep drainage were very low at the two sites (lower than atmospheric deposition). The largest fluxes of nutrients deep into the soil came when the previous stands were clearcut, and post-logging residues as 


\section{Classic model 1}

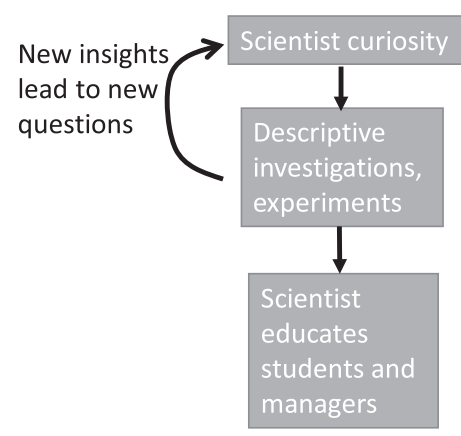

Classic model 2

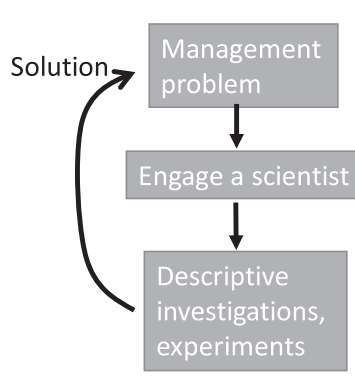

A more powerful model

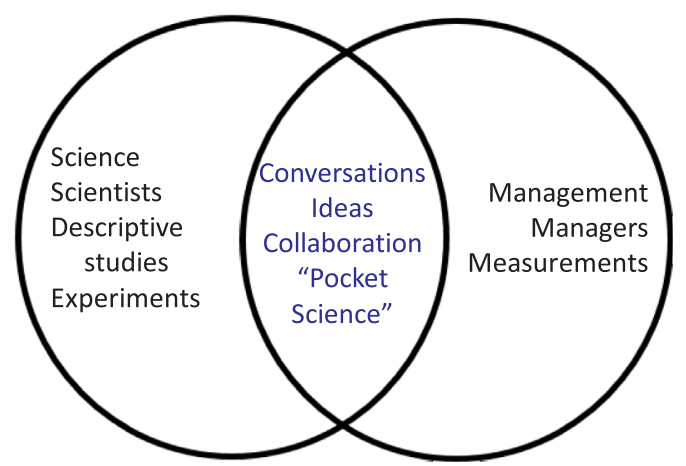

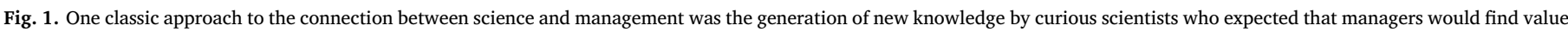

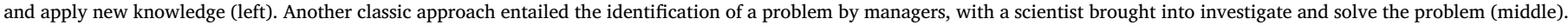

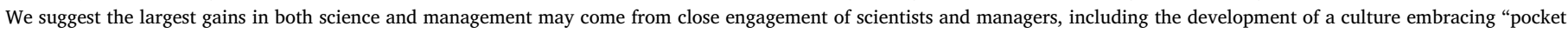
science" (right, described in more detail in the text).

A

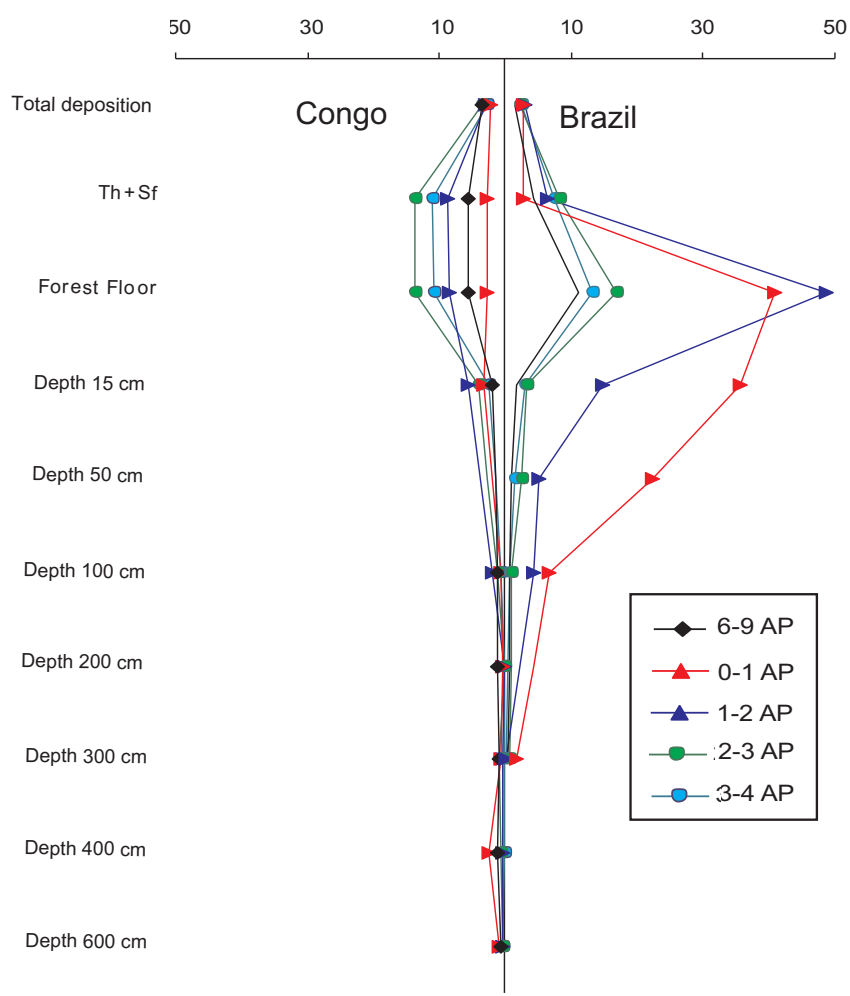

B

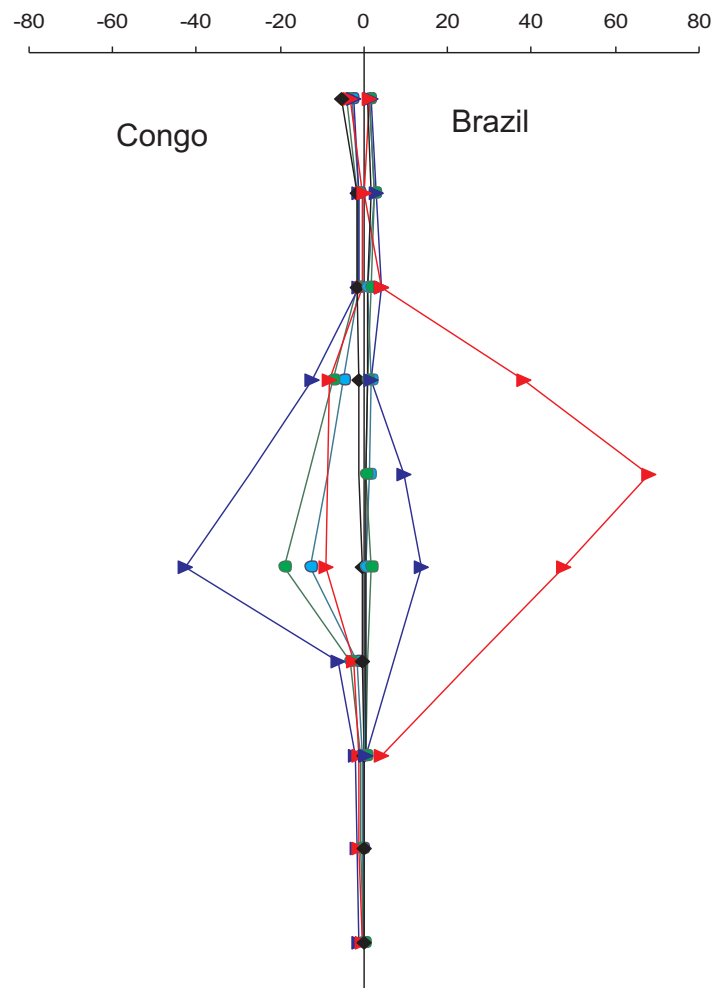

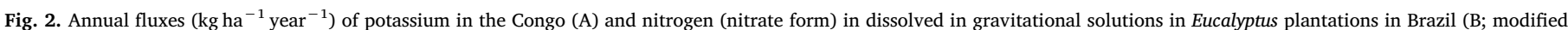

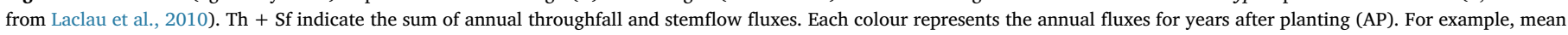

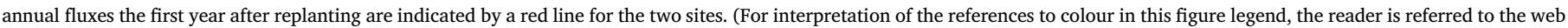
version of this article.)

well as fertilizers $\left(120 \mathrm{~kg} \mathrm{Nha}^{-1}\right.$ and $100 \mathrm{~kg} \mathrm{Kha}^{-1}$ in Brazil) provided pulses of nutrients in the upper soil for the early growth of planted trees (Fig. 2). However, nutrient concentrations remained very low at a depth of $3 \mathrm{~m}$ throughout the rotation. The main factors controlling soil solution chemistry were similar at the two sites: (i) high nutrient demand the first after planting to support growth of nutrient-rich leaves and fine roots, (ii) very fast root growth in deep soil layers (Pinheiro et al., 2016), (iii) high water demand from the first year after planting onward (Christina et al., 2017), which enhances the transport of ions up to the roots by mass flow, and (iv) slow velocity of ion displacement downward in gravitational soil solutions due to both root uptake and adsorption of ions on soil organic matter, oxides and clay minerals (Laclau et al., 2003, Mareschal et al., 2013). Low losses of nutrients by deep drainage have been confirmed in other tropical eucalypt plantations managed in short rotation (e.g. Silva et al., 2013).

The generality of the factors accounting for a sharp decrease in nutrient concentrations throughout the transfer of gravitational solutions in very deep soil layers led many forest companies to test effectiveness of fewer, larger applications of fertilizer, potentially with the same yield increases, lower cost, and low risk of large leaching losses of nutrients from the sites. The understanding of the main factors driving the chemistry of soil solutions led therefore to a simplification of fertilization regimes over huge areas of eucalypt plantations on deep soils in Brazil. 


\subsection{The influence of soil aeration on forest communities and productivity}

Coastal rainforests on northern Vancouver Island in Canada showed highly variable regeneration after logging. Poor regeneration of conifers on sites previously occupied by old-growth forests of western redcedar (Thuja plicata) and western hemlock (Tsuga heterophylla; CH forests) contrasted with better regeneration following logging of old-growth forests of hemlock and amabilis fir (Abies amabilis, HA forests). Forest managers engaged university and government scientists to investigate the causes of the poor regeneration and recommend possible silvicultural remedies. The scientists developed experiments to examine the effects of fertilization, weed control, soil scarification, tree species and planting densities. The experiments showed revealed strong deficiencies of $\mathrm{N}$ and $\mathrm{P}$ in regenerating $\mathrm{CH}$ sites. Silvicultural recommendations for these sites were: site prepare to control competing ericaceous vegetation (salal), promptly planting of conifers at high densities ( $\geq 1500$ stems/ha), and fertilization with both $\mathrm{N}$ and $\mathrm{P}$ at planting, with repeated $\mathrm{N}$ fertilization till crown closure.

But why were nutrient supplies so much lower for $\mathrm{CH}$ sites than for nearby HA sites? Ecological experiments tested 5 hypotheses:

(1) The ericaceous shrub, salal, is abundant on $\mathrm{CH}$ cutovers and could through competition and release of tannins that interfere with $\mathrm{N}$ mineralization, hinder growth of conifers. Experiments showed that salal removal provided little if any benefit to conifers, disproving this hypothesis.

(2) Differences between HA and $\mathrm{CH}$ stands could be a matter of stand age, with progressive $\mathrm{N}$ tie-up in biomass as HA stands transitioned into $\mathrm{CH}$ stands. No evidence was found that the stands represented a development trajectory within any sites, disproving this hypothesis.

(3) The historic disturbance that led to the establishment of HA forests may have included very large windthrows that "rejuvenated" low-nutrient topsoil by exposing deeper, less-weathered soil. However, soil mixing and scarification did not stimulate mineralization in $\mathrm{CH}$ soils, disproving this hypothesis.

(4) Western redcedar in $\mathrm{CH}$ forests might create the low nutrient conditions by slowing rates of nutrient cycling. Common-garden species trials did not show a depression of nutrient cycling, leaving this hypothesis invalidated.

(5) Although the HA and $\mathrm{CH}$ forest types were thought to occur on the same soil types (same topography, same soil physical properties), scientists observed small differences in moisture status that may bracket a critical soil aeration (redox) threshold. Under the high precipitation regime, a small difference in slope position or drainage was sufficient to cause the sites to diverge ecologically and nutritionally (Fig. 3). Experimental drainage of $\mathrm{CH}$ sites showed marked increases in growth, supporting the redox hypothesis.

The cost of improving drainage to convert $\mathrm{CH}$ sites to the physical condition of HA sites would be very high. Alternatively, long-term (21-year) results from a silvicultural field trial demonstrated that major gains in growth rates could be achieved simply by repeated fertilization, with or without expensive drainage. Fertilization of $\mathrm{CH}$ sites led to increases in growth of redcedar and hemlock of $100 \mathrm{~m}^{3} \mathrm{ha}^{-1}$. Curiously, the growth response on higher-productivity HA sites to fertilization was so large $\left(200 \mathrm{~m}^{3} \mathrm{ha}^{-1}\right.$ for cedar and $270 \mathrm{~m}^{3} \mathrm{ha}^{-1}$ for hemlock) that silvicultural recommendations shifted to (i) plant hemlock and redcedar on HA sites and fertilize repeatedly, and (ii) plant redcedar on $\mathrm{CH}$ sites and expect growth rates to be quite slow.

This long-term research program demonstrates the synergies that occur when long-term, well-replicated silvicultural field trials are coupled with curiosity-driven ecological science that is aimed at understanding the ecosystem in question - an understanding that transcending simple expectations based on ecosystem classification.

\section{Ecological insights based on forest landscapes}

The classic experimental designs that are applied in single stands at single points in time restrict the statistical population of inference to just an individual stand (see Binkley, 2008). An assumption may be made that the response at one site would be representative of many sites, but geographic variation across landscapes and regions is usually too large to support this assumption. Insights that apply to the scale of forests across landscapes may be developed from landscape-scale inventories, investigations and experiments. The importance of distributing effort at the same scale where

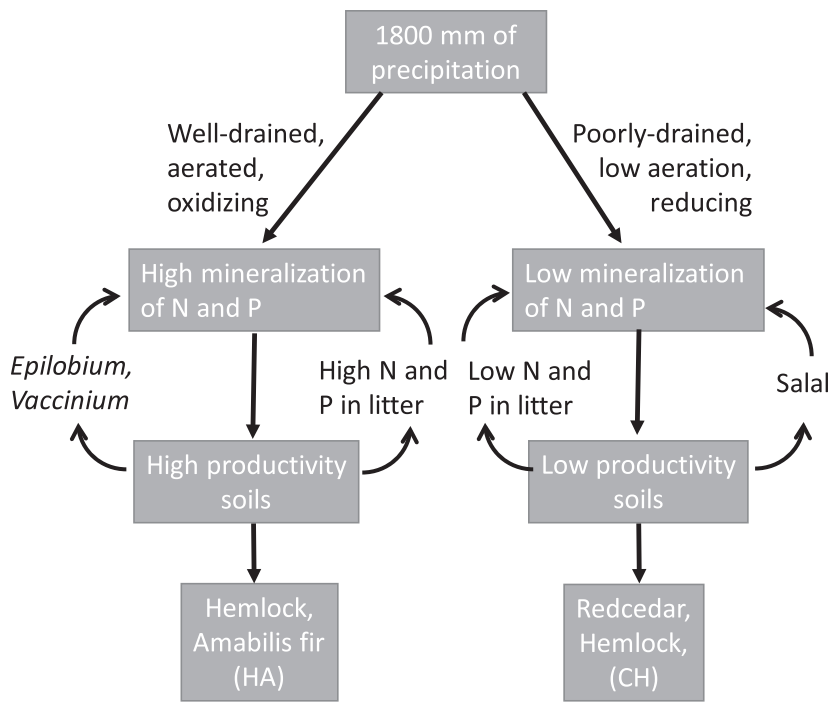

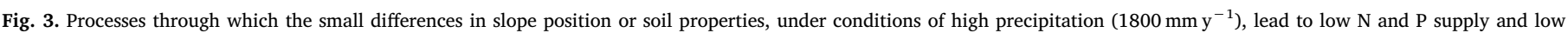

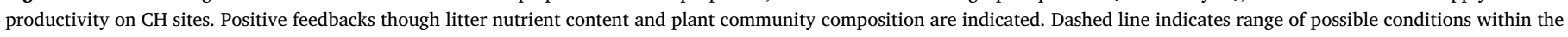
CH site type (based on Prescott et al., 2013). 


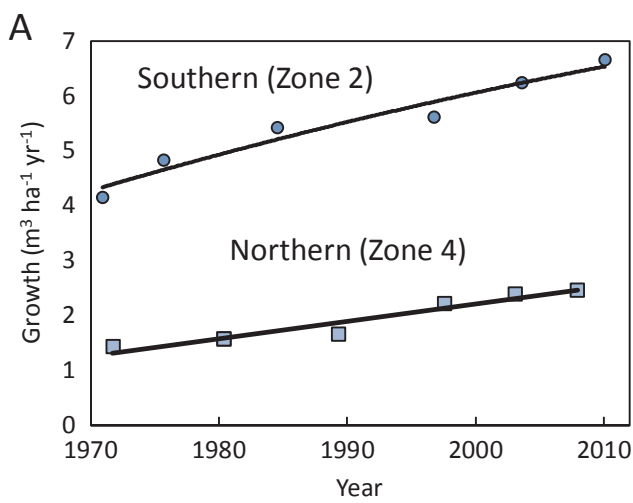

B

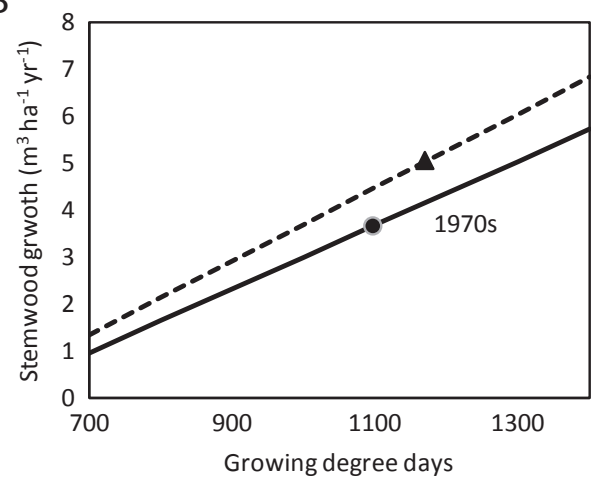

Fig. 4. The national scale of forest inventory sampling in Finland showed large increases across the country over the past 40 years (A, after Henttonen et al., 2017). Kauppi et al. (2014) found that growing degree days increased by an average of about $27 \%$ during this period (B), but that growth did not accelerate along a constant line (mean value black dot), but rather a new relationship was evident (mean value triangle), indicating a change in growth factors other than warming, or even that warming was not a major factor.

new insights will be applied has been a cornerstone of forest inventories for generations. Forest inventories have a very long history on both private and public lands, with goals of determining the current state of forest structures, and often rates of change (especially tree growth). The data collected in inventories can provide ecological insights to improve scientific understanding, across very large populations of inference.

\subsection{Long-term changes in forest growth across Finland}

The climate of northern Europe has been warming for more than one and a half centuries. The growth of Finnish forests increased slightly during the first half of the 20th century, followed by rapid increases during the early 1970s (Fig. 4; see also Helama et al., 2005). An important question in ecological science is whether the increase in temperature would account for increased forest growth. Kauppi et al. (2014) examined whether the observed 20\% increase in growing degree days could account for the increased forest growth. They correlated rising growth rates with rising temperatures, and concluded that warming might explain $52 \%$ of the observed growth increase. However, the average growth expected for a site with 1200 growing degree days in the mid-20th century was $4.4 \mathrm{~m}^{3} \mathrm{ha}^{-1} \mathrm{yr}^{-1}$, compared to the current rate of $5.3 \mathrm{~m}^{3} \mathrm{ha}^{-1} \mathrm{yr}^{-1}$, indicating that growth increased even when climate was held constant.

Correlations of patterns between forests and climate test for associations between variables, but correlations may not provide strong evidence of causation, especially where more than one independent factor is also changing. The intensity of silviculture increased across Finland during the period of climate change, and both factors may influence forest growth. A closer examination of multiple, interacting factors led Hentonnen et al. (2017) to conclude that about 2/3 of the increased growth across Finland (Fig. 4) resulted from increased density of trees (higher growing stock) and intensified management. Only about one-third of the increase could be attributed to environmental drivers (including warming, nitrogen deposition, or atmospheric $\mathrm{CO}_{2}$ enrichment), rather than one-half as estimated by Kauppi et al. (2014). The value of insights from analyses of landscape-scale patterns in forests depends very strongly on the ability of an investigation to weigh (and test) potential driving factors and their likely interactions.

The importance of climate to increased growth of Finnish forests is particularly important for extrapolation to other boreal forests. The changing climate in Finland may be representative of broad areas, but the changes in forest management in Finland would not likely represent forests in areas such as northern Russia. Many other countries (and forest companies) have intensive inventories that could be explored for ecological insights into driving factors.

\subsection{Fire risk and management in mountain ash forests}

Fires are of course an important driver of most forests around the world, and the intensity and severity of fires depends in part on the amount and structure of fuels within stands and across landscapes. A hypothesis might be advanced that intensively managed, fast-growing forests of mountain ash (Eucalyptus regnans) are more prone to severe, stand-replacing fires than old-growth forest structures (Fig. 5; cf. Lindenmayer et al., 2011). Controlled experiments to test this hypothesis are not feasible, but the hypothesis might be testable with landscape-scale patterns of fires over large areas and long periods.

The mountain ash forests in Victoria in southern Australia experienced severe fire years in 1939 and 2009. The extent of the severe fires can be contrasted between areas of differing management and stand structures to test the hypothesis that old, unmanaged forests have a lower risk of severe fire. The 1939 fires burned about $20 \%$ of forests designated for preservation in parks, compared with almost $60 \%$ of the state forest designated for management. In 1939, both land tenures were characterized by extensive old growth forests; the greater fire extent in the state forests (Fig. 6 , Adams et al., in preparation) likely related to these forests being designated on drier portions of landscapes compared with parks that were identified in large part for wetter sites designated as parks for municipal water supplies. By 2009, much of the state forest area had been harvested and regenerated to young forests, in addition to the younger forests that recovered after the 1939 fires. The park forests remained largely in old-growth forests. The hypothesis that fire risks would be lower in old-growth forests would lead to a prediction that severe fire weather in 2009 would lead to less burn area in park forests than in younger, managed state forests. The hypothesis was rejected, as the extent of severe fire was similar for both land tenures. Given that managed, younger state forests generally occurred on drier landscapes, the similar fire extents would indicate that younger forests likely have a lower risk of severe fire, the opposite of the hypothesized pattern.

\subsection{Twinplots to connect forest inventory with nutritional limitation assessments}

Silvicultural experiments are most powerful when they provide insights into responses at the scales across the range of sites under management. These experiments are even more useful if the variation in outcomes among sites can be parsed by easily measured site features, such as soil types. The development of silvicultural insights does not need to be restricted to the domain of forest researchers; very simple approaches by forest managers can provide very profitable results. An example is the "twinplot" approach (Stape et al., 2006), where forest inventory plots are paired with 

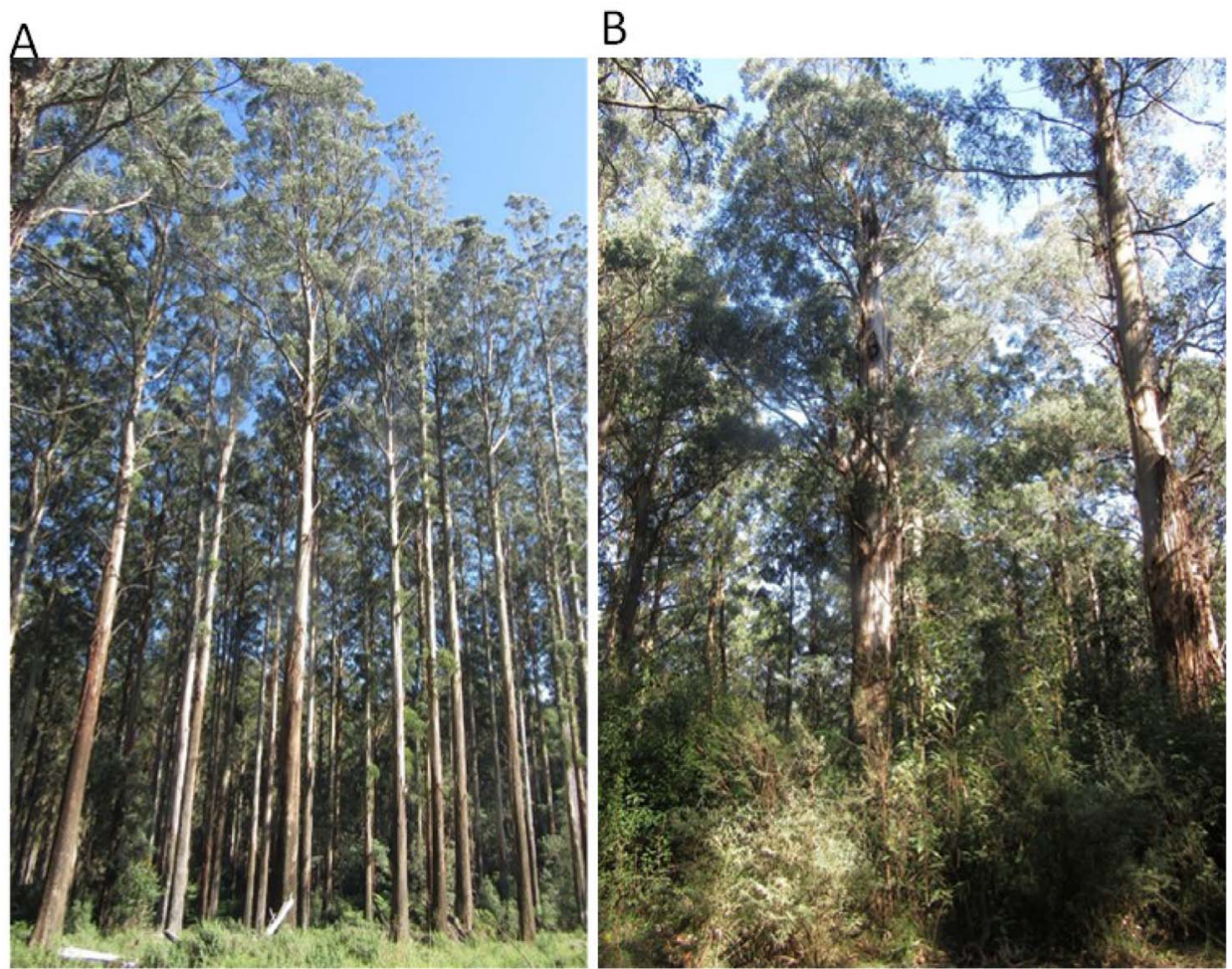

Fig. 5. The risk of severe, stand-replacing fire likely depends in part on the structure of forests, and how these structures influence fuel sizes, total fuel loadings, and ability of fire to propagate. Which of these mountain ash (Eucalyptus regnans) stands has a higher risk of severe fire, the 100-year-old managed forest (A), or the old-growth forest (B) that has not had a major disturbance in over two centuries?

an adjacent treatment plot. The treatment might be fertilization, thinning, weed control or other operation that might enhance yields. The cost of establishing twinplots is minimal, as the cost of travel is near zero if combined with inventory operation, and the marginal cost of treating small plots is very small compared to costs of operational forest management. Post-treatment measurements may focus simply on tree diameter response. Fig. 7 illustrates the outcome of an operational twinplot assessment of nutrient limitation of a company's lands in Brazil, showing that a high average response to fertilization could be usefully examined in terms of site factors (such as soil texture).

\section{Pocket science: Crossing the line between science and management}

Many major questions in forest ecology and management require the classic resources and expertise of major research projects and specialized scientists. However, many opportunities for improving management can come from much simpler approaches, where managers build in opportunities to learn into each treatment unit. The twinplot approach is one example of this pocket science approach (Binkley and Fisher, 2013). The simplest (and maybe most useful) pocket science scheme would entail leaving a small untreated unit that may provide insights into "what might happen?" if the treatment had not been applied. Fig. 8 shows a restoration treatment in a mixed conifer/aspen forest in Grand Canyon National Park, where an untreated (control) plot was retained. Managers and visitors understand the responses to treatment in ways that would not be so evident if the entire unit had been treated uniformly. The retention of untreated plots can be especially useful for learning if the treatment led to unintended consequences. The use of small fenced exclosures to prevent grazing and browsing by livestock and wildlife is a classic is example of this sort of pocket science (cf., Stohlgren et al., 1999).

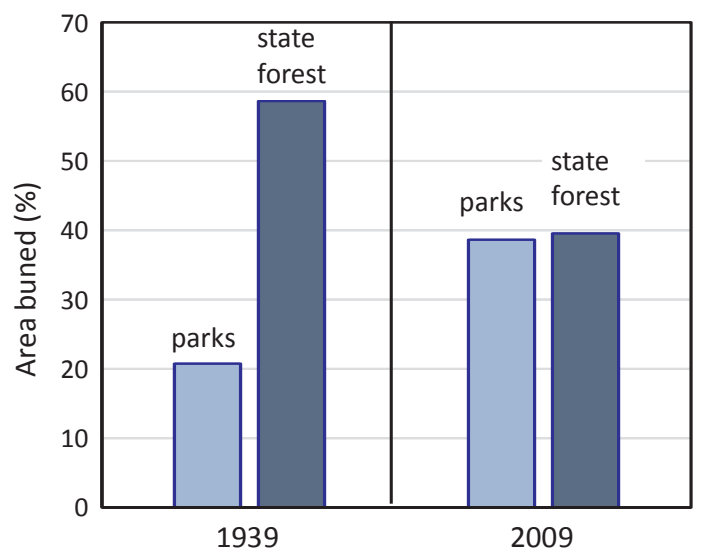

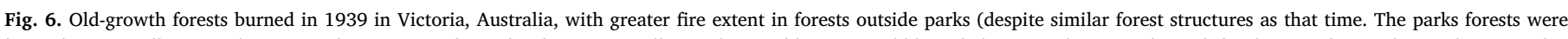

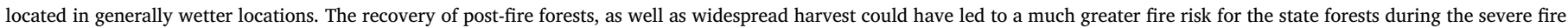

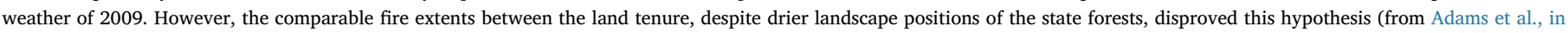
preparation). 

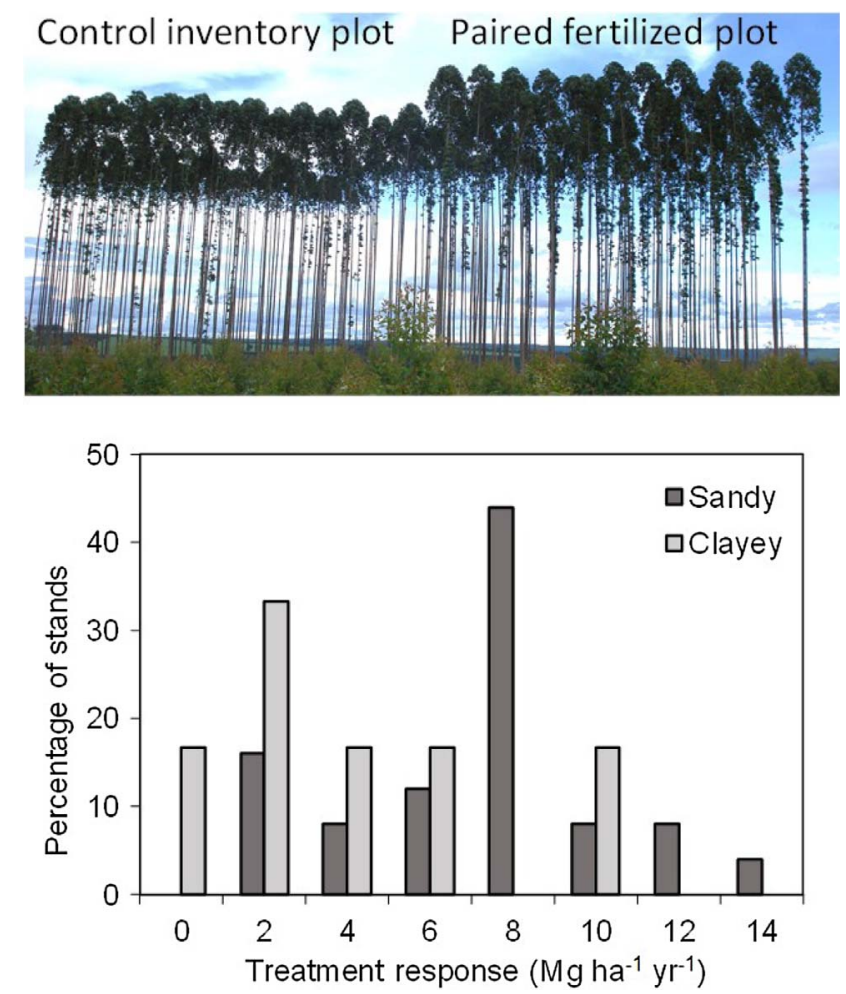

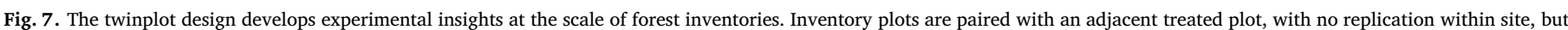

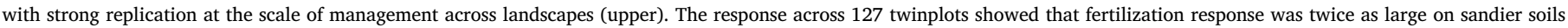
(Stape et al., 2006), and the distributions of responses can be used in a decision tree analysis for optimum selection of treatments by site types (cf. Binkley and Fisher, 2013).

More active pocket science could entail applying a more intensive treatment in a small (representative) plot than the level applied across the majority of the unit. For example, operational fertilization could be applied across a unit, with a small portion of the unit receiving a double dose. If this approach were repeated across many units, managers would have an opportunity to learn if there might be profitable opportunities for raising (or reducing) fertilization rates, and whether greater investments in classical research would likely payoff.
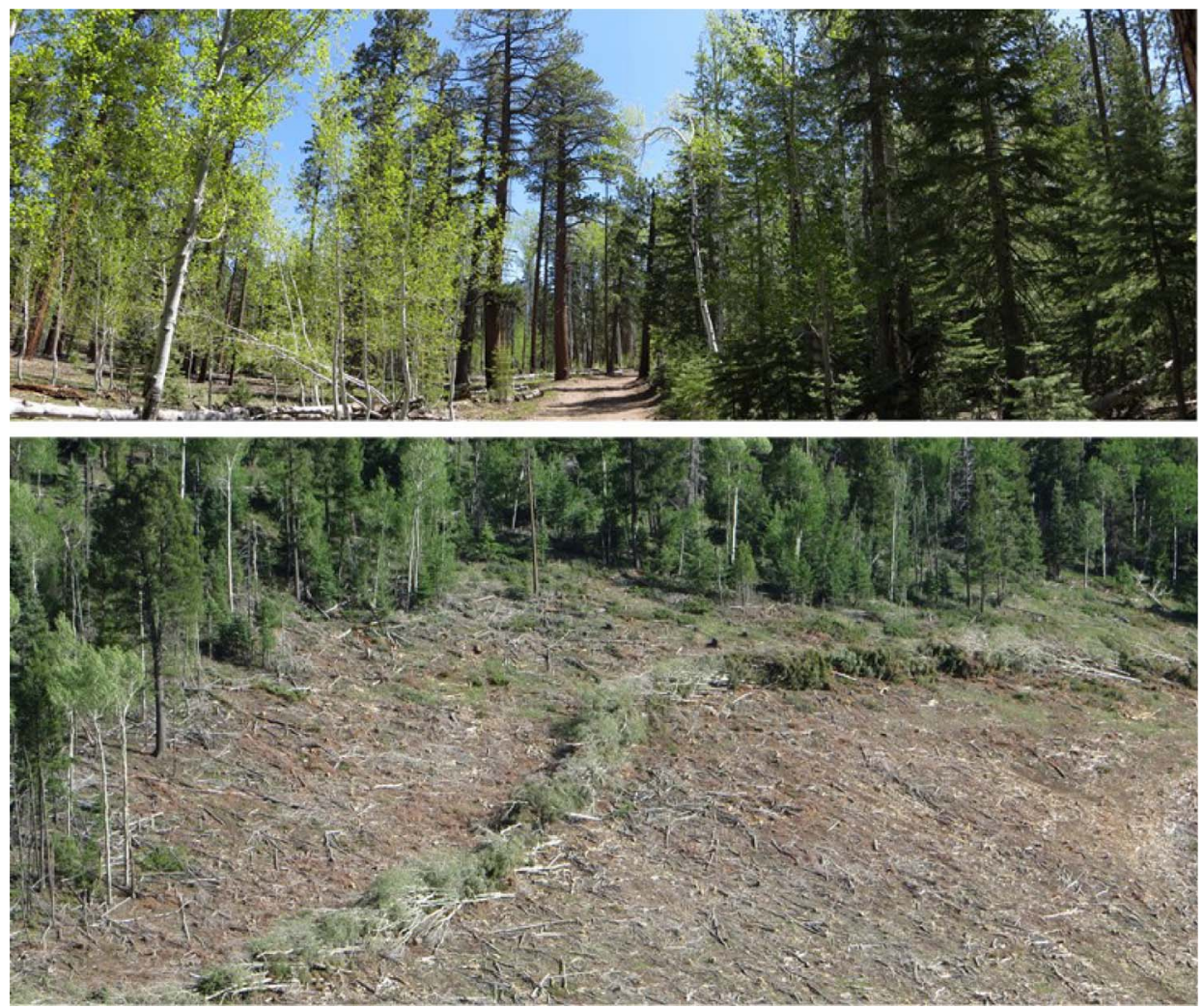

Fig. 8. The left side of the upper photograph shows a forest restoration treatment, with an untreated control plot retained on the right side. The retention of untreated parcels within operational management units is a key feature of pocket science that provides opportunities for managers to learn about expected and unexpected outcomes. The lower photograph shows a brush fence built in a clearcut to discourage browsing of regenerating aspen (the lower right side is within the area surrounded by the brush fence). The fencing treatment did not follow the boundary of the clearcut, providing an opportunity for managers to learn what would have happened if the fence had not been built. 
Learning from pocket science treatments does not require expensive measurements. Most responses that would be large enough to lead to improved management would be apparent with simple measurements such as tree densities and diameters. In some cases, repeated photographs may capture the essential information without further measurement. A pocket science program could be developed based on the collection of barebones information: GPS locations, photo points for repeat photography, and minimal record keeping. A day or two per year could be allocated to revisiting pocket science projects, including showing the responses to colleagues to spread the learning opportunities.

\section{Conclusions}

Future improvements in our understanding and management of the world's forests will build on an expanding foundation of knowledge and insights. This foundation will be built in part from classic experimentation by scientists exploring curiosity-driven inquiry into basic ecological sciences (Fig. 1). The foundation will also include knowledge derived from the opportunities afforded by examining landscape-scale patterns in managed and unmanaged forests. All this information will come from locations that differ from the actual units that are managed by each forester, so locally based pocket science may form the third part of the ecological knowledge foundation for improved forest management.

\section{References}

Adams, M.A., Gharun, M., Bell, T.A., in preparation. Water availability, logging, fire and landscape traps in Mountain Ash forests.

Aplet, G.H., McKinley, P.S., 2017. A portfolio approach to managing ecological risks of global change. Ecosyst. Health Sust. 3, 1-15.

Binkley, D., 2008. Three key points in the design of forest experiments. For. Ecol. Manage. 255, 2022-2023.

Binkley, D., Fisher, R.F., 2013. Ecology and Management of Forest Soils. Wiley, New York, pp. 347.

Christina, M., Nouvellon, Y., Laclau, J.-P., Stape, J.L., Bouillet, J.-P., Lambais, G.R., le Maire, G., 2017. Importance of deep water uptake in tropical eucalypt forest. Funct. Ecol. 31, 509-519.

Gonçalves, J.L.M., Alvares, C.A., Ferraz, S.F.B., Lima, W.P., Higa, A.R., Silva, L.D., Alfenas, A.C., Stahl, J., Brancalion, P.H.S., Hubner, A., Bouillet, J.-P., Laclau, J.-P., Nouvellon, Y., Epron, D., 2013. Joining genetic and silvicultural strategies to minimize abiotic and biotic constraints in eucalypt plantations of Brazil. For. Ecol. Manage. $301,6-27$.

Helama, S., Lindholm, M., Timonen, M., Eronen, M., 2005. Multicentennial ringwidth chronologies of Scots pine along a north-south gradient across Finland. Tree-Ring Res. 61 (1), 21-32.

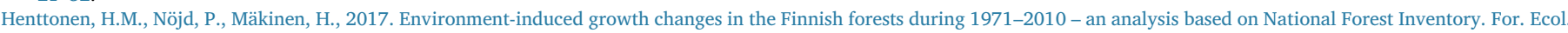
Manage. 386, 22-36.

Kauppi, P.E., Posch, M., Pirinen, P., 2014. Large impacts of climatic warming on growth of boreal forests since 1960. PLoS ONE 9, 1-6.

Laclau, J.-P., Ranger, J., Nzila, J.D., Bouillet, J.-P., Deleporte, P., 2003. Nutrient cycling in a clonal stand of Eucalyptus and an adjacent savanna ecosystem in Congo. 2. Chemical composition of soil solutions. For. Ecol. Manage. 180, 527-544.

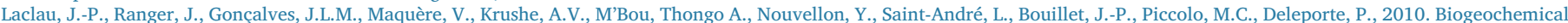
cycles of nutrients in tropical Eucalyptus plantations. Main features shown by intensive monitoring in Congo and Brazil. For. Ecol. Manage. 259 , $1771-1785$.

Lindenmayer, D.B., Hobbs, R.J., Likens, G.E., Krebs, C.J., Banks, S.C., 2011. Newly discovered landscape traps produce regime shifts in wet forests. Proc. Nat. Acad. Sci. USA 115887-115891.

Mareschal, L., Laclau, J.P., Nzila, J.D.D., Versini, A., Koutika, L.S., Mazoumbou, J.C., Deleporte, P., Bouillet, J.P., Ranger, J., 2013, Nutrient leaching under Eucalyptus plantations managed in short rotations after afforestation of an African savanna: a 14-year time series. For. Ecol. Manage. 307, $242-254$.

Matonis, M.S., Binkley, D., Franklin, J., Johnson, K.N., 2016. Benefits of an "undesirable" approach to natural resource management. J. For. 114 , $658-665$.

Pinheiro, R.C., de Deus Jr., J.C., Nouvellon, J., Campoe, O.C., Stape, J.L., Lívia, L.A., Guerrine, I.A., Jourdan, C., Laclau, J.-P., 2016. A fast exploration of very deep soil layers by Eucalyptus seedlings and clones in Brazil. For. Ecol. Manage. 366, 143-152.

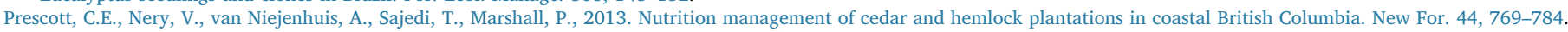

Silva, P.H.M., Poggiani, F., Libardi, P.L., Gonçalves, A.N., 2013. Fertilizer management of eucalypt plantations on sandy soil in Brazil: initial growth and nutrient cycling. For. Ecol. Manage. 301, 67-78.

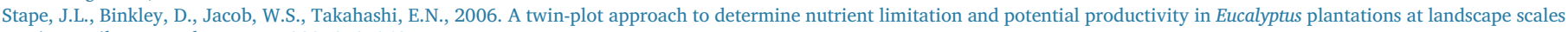
in Brazil. For. Ecol. Manage. 223, 358-362.

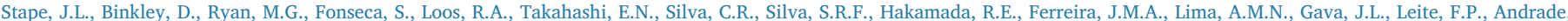
H.B., Alves, J.M., Silva, G.G.C., Azevedo, M.R., 2010. The Brazil Eucalyptus potential productivity project: influence of water, nutrients and stand uniformity on wood production. For. Ecol. Manage. 259 (9), 1684-1694.

Stohlgren, T.J., Schell, L.D., Venden Heuvel, B., 1999. How grazing and soil quality affet native and exotic plant diversity in Rocky Mountain grasslands. Ecol. Appl. 9, 45-64.

Dan Binkley*

School of Forestry, Northern Arizona University, Flagstaff, AZ 86011, USA E-mail address: Dan.Binkley@alumni.ubc.ca

Mark Adams

Faculty of Agriculture, Food, and Natural Resources C81, University of Sydney, NSW 2006, Australia

Todd Fredericksen

Ferrum College, Ferrum, VA 24088, USA

Jean Paul Laclau

Cirad, UMR Eco\&Sols, 2 Place Viala - Bât. 12, 34060 Montpellier cedex 2, France

Harri Mäkinen

Natural Resources Institute Finland, c/o Aalto University, PO Box 16200, 00076 Aalto, Finland

Cindy Prescott

Department of Forest and Conservation Sciences, University of British Columbia, 3040-2424 Main Mall, Vancouver, BC V6T1Z4, Canada 